\title{
Resolution of Cardiac Symptoms through Preoperative Intravenous Iron Supplementation in a Cancer Patient
}

\author{
Anja-Claudine Nawratil1, Marc Moritz Berger ${ }^{*}{ }^{*}$, Alexander Geisberger² \\ ${ }^{1}$ Department of Anesthesiology, Perioperative and General Critical Care Medicine, University Hospital Salzburg, Paracelsus \\ Medical University, Salzburg, Austria \\ ${ }^{2}$ ViforPharma Austria, Vienna, Austria \\ Email: a.nawratil@salk.at, ‘ma.berger@salk.at, alexander.geisberger@viforpharma.com
}

How to cite this paper: Nawratil, A.-C., Berger, M.M. and Geisberger, A. (2019) Resolution of Cardiac Symptoms through Preoperative Intravenous Iron Supplementation in a Cancer Patient. Case Reports in Clinical Medicine, 8, 173-180.

https://doi.org/10.4236/crcm.2019.87021

Received: May 12, 2019

Accepted: July 6, 2019

Published: July 9, 2019

Copyright $\odot 2019$ by author(s) and Scientific Research Publishing Inc. This work is licensed under the Creative Commons Attribution International License (CC BY 4.0).

http://creativecommons.org/licenses/by/4.0/

(c) (i) Open Access

\begin{abstract}
Cardiologic assessment was conducted on a 78-year-old male patient scheduled for elective aortic valve surgery who complained of angina and dyspnea that had arisen over the previous few months. Evaluation showed stable coronary artery disease and iron deficiency anemia (hemoglobin, $7.7 \mathrm{~g} / \mathrm{dL}$ ). Colonoscopy revealed a non-stenosing carcinoma of the right colonic flexure that was causing chronic blood loss. The interdisciplinary tumor board of the hospital decided that his need for an extended right hemicolectomy followed by resection of two pulmonary nodules that were suspicious of metastatic lesions had priority over his cardiac surgery. Prior to abdominal surgery, the patient received $4 \times 500 \mathrm{mg}$ intravenous iron (Ferric-Carboxymaltose) over 2 weeks, for correction of iron deficiency and optimization of hemoglobin concentration. This treatment led to rapid improvement of his angina and exertion-induced dyspnea. His hemoglobin concentration continued to rise even after completion of the iron supplementation, and reached normal levels before thoracoscopic removal of the lung nodules, which took place 1 month after resection of the colon tumor. The patient remained in good clinical condition without any need for blood transfusions. As follow-up visits showed persistent abatement of angina and dyspnea, aortic valve surgery and other cardiac interventions were no longer deemed necessary.
\end{abstract}

\section{Keywords}

Patient Blood Management, Iron Deficiency, Anesthesia, Anaemia, Heart Failure

\section{Introduction}

The term patient blood management was coined in 2005, and was defined as an 
evidence-based, multidisciplinary approach that is aimed at optimization of the care of patients who might need transfusions and the use of blood products [1]. Preoperative anemia, blood loss, and red cell transfusions have been identified as risk factors in the surgical setting. Muñoz et al. showed that these risk factors adversely affect postoperative infection rates, length of hospital stay, and mortality [2]. To avoid these adverse effects, the strategic adoption of patient blood management in surgical practice is widely recommended [3].

Patient blood management rests on three pillars of care: detection and treatment of preoperative anemia; reduction of perioperative blood loss; and harnessing and optimization of the patient-specific physiological reserve of anemia [3]. A bundle of measures is used to achieve these goals, including treatment of any underlying disease, the ideal timing for surgery, adoption of minimally invasive techniques, and immediate correction of coagulopathy, among others.

Bloodless therapeutic modalities, such as the use of erythropoietin (EPO) and intravenous iron supplementation, have moved into the focus now that the risks of unnecessary blood transfusions are increasingly being recognized. Lin et al. conducted a systematic review of 39 studies showing that transfusion rates can be significantly reduced by a short preoperative regimen of EPO or a single dose of EPO plus intravenous iron administered in the preoperative or intraoperative period [4]. Litton et al. included 72 studies in a meta-analysis according to which intravenous iron therapy is associated with increased hemoglobin levels and reduced risk of the need for red blood cell transfusion [5].

Patient blood management has been demonstrated to be worth the associated efforts. In a retrospective observational trial conducted in a total of 605,046 patients, Leahy et al. showed that a health-system wide patient blood management program can improve patient outcomes and reduce product-related costs [6]. The patient outcomes that were assessed in this study included the use of blood products, in-hospital mortality, length of hospital stay, hospital-acquired infections, and acute myocardial infarction or stroke. However, the benefits of patient blood management can be extended beyond just the surgical setting. Here, we describe the case of a patient who experienced significant collateral improvement to his cardiac situation due to preoperative iron supplementation after an unexpected diagnosis of cancer.

\section{Case Presentation}

A 78-year-old male was admitted to the Cardiology Unit in mid-March 2018 for diagnostic assessment prior to elective aortic valve surgery. He reported signs of coronary artery disease and heart failure, with a history of angina that had built up over the previous few months, and dyspnea triggered by slight exertion. His sociodemographic and anamnestic characteristics are summarized in Table 1. Coronary angiography showed stable two-vessel disease, including stenosis of the left anterior descending artery and chronic total occlusion of the right coronary artery. Echocardiographic evaluation revealed intermediate to high-grade 
Table 1. Sociodemographic and anamnestic characteristics.

\begin{tabular}{|c|c|c|}
\hline Family History & Medical History & Therapy \\
\hline Father: Pancreatic carcinoma & Cancer of the rectum 1998 & Abdomino-perineal extirpation \\
\hline Brother: Pancreatic carcinoma & Bladder cancer 2012 G1, pTa & $\begin{array}{c}\text { Transurethral resection } \\
\text { of the prostate } 2012\end{array}$ \\
\hline Son: Prostate gland carcinoma & $\begin{array}{l}\text { Adenocarcinoma of the } \\
\text { rectum } 03 / 2018 \mathrm{G} 3 \mathrm{~T} 2 \\
\text { pN0 }(0 / 20), \text { cM0 }\end{array}$ & Right hemicolectomy 04/2018 \\
\hline
\end{tabular}

aortic valve stenosis and grade I-II aortic valve insufficiency. However, his left ventricular function appeared to be preserved, with an ejection fraction of $\sim 60 \%$.

Laboratory tests showed pronounced iron deficiency anemia, with an erythrocyte count of $4.0 \mathrm{~T} / \mathrm{L}$, hemoglobin of $8.0 \mathrm{~g} / \mathrm{dL}$, and hematocrit of $26.6 \%$ (Figure 1). His iron levels were low (17 $\mu \mathrm{g} / \mathrm{dL}$; normal range, $80-160 \mu \mathrm{g} / \mathrm{dL}$ ), as was his transferrin saturation (3\%; normal range, $16 \%$ - 45\%) and serum ferritin levels ( $6 \mu \mathrm{g} / \mathrm{L}$; normal range, $50-310 \mu \mathrm{g} / \mathrm{dL}$ ). This was accompanied by correspondingly high transferrin $(359 \mathrm{mg} / \mathrm{dL}$; normal range, 172 - $344 \mathrm{mg} / \mathrm{dL})$ and soluble transferrin receptor $(14.24 \mathrm{mg} / \mathrm{L}$; normal range, $2.16-4.54 \mathrm{mg} / \mathrm{L})$. As the patient had a history of rectal carcinoma that had been successfully treated approximately 20 years ago, colonoscopy was performed in search of the cause of his anemia. This investigation revealed a nonstenosing malignant tumor of the right colonic flexure, with a size of $4 \mathrm{~cm} \times 5 \mathrm{~cm}$. Staging showed two pulmonary nodules of the right lung that were suspected to be metastatic lesions.

The interdisciplinary tumor board of the hospital agreed on two-stage surgery including extended right hemicolectomy and resection of the pulmonary nodules, while any cardiac intervention was postponed. Optimizing the red blood cell mass was mandatory prior to surgery. To this end, the patient received intravenous iron supplementation on an outpatient basis, which started on April 4, 2018. At that time, his hemoglobin had further declined to $7.7 \mathrm{~g} / \mathrm{dL}$ (Figure $1)$. The patient was in poor general condition, intolerant to exercise, and suffered shortness of breath even when speaking. However, he showed no edema or other signs of heart failure.

Overall, $2000 \mathrm{mg}$ intravenous iron (Ferric-Carboxymaltose) was administered over 2 weeks, as four sessions with $500 \mathrm{mg}$ in each. One week after the start of treatment, the condition of the patient had improved considerably, and his walking dyspnea was completely resolved. Also, he reported reduction in his angina symptoms.

The last intravenous iron dose was administered on April 19, 2018. Laboratory tests performed on April 18, 2018, revealed markedly improved red blood cell parameters, with an erythrocyte count of $4.8 \mathrm{~T} / \mathrm{L}$, hemoglobin of $10.8 \mathrm{~g} / \mathrm{dL}$, and hematocrit of $36.0 \%$ (Figure 1). Surgical resection of the colon tumor was scheduled for April 30, 2018. At the time of his hospital admission on April 29, 2018, his hemoglobin had risen further to $12.1 \mathrm{~g} / \mathrm{dL}$ (hematocrit, $37.2 \%$ ), and the patient appeared to be in good clinical condition. 


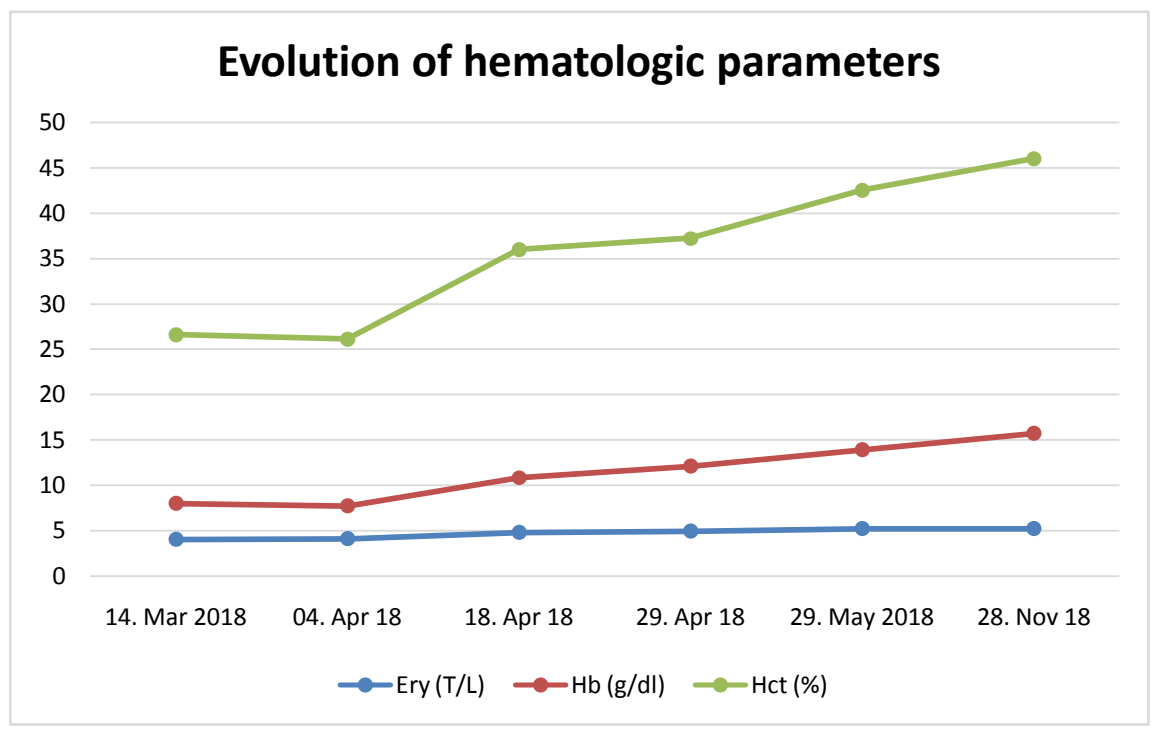

Figure 1. Evolution of the patient erythrocyte counts, hemoglobin and hematocrit levels.

Surgery was performed successfully on the next day. His postoperative hemoglobin concentration never fell below $10.1 \mathrm{~g} / \mathrm{dL}$. Histological examination of the colon tumor showed a mucinous adenocarcinoma with a maximum diameter of $3 \mathrm{~cm}$ (G3, pT2, PN0 [0/20], M1). The patient was hemodynamically stable throughout the postoperative period, and did not require any blood transfusions. He was discharged on postoperative day 9.

One month after the hemicolectomy, i.e., on May 30, 2018, the lung nodules were resected via video-assisted thoracoscopic surgery. Without having received any further iron supplementation in the meantime, the patient showed normal red blood cell parameters at the preoperative laboratory assessment performed on May 29, 2018 (erythrocyte count, 5.2 T/L; hemoglobin, $13.9 \mathrm{~g} / \mathrm{dL}$; hematocrit, $42.5 \%)$. He reported being able to climb two flights of stairs and to have extended walks without any angina or dyspnea. Postoperatively, his hemoglobin levels remained above $11.7 \mathrm{~g} / \mathrm{dL}$. Neither of the two lung nodules showed signs of malignancy. According to histological evaluation, one nodule was a hamartoma, while the other one was an anthracotic lymph node, which was left in situ. The patient was discharged on the third postoperative day. From the oncological point of view, no further interventions were considered necessary, apart from his follow-up visits.

The cardiological evaluation performed a month later, on June 29, 2018, did not indicate the need for cardiac intervention. Echocardiographic assessment still showed moderate aortic stenosis with preserved left ventricular function (ejection fraction, 55\% - 60\%), but his angina and dyspnea had significantly improved, and the patient did not report any heart-related limitations in his daily life. Follow-up visits were arranged.

Another cardiological evaluation performed on September 25, 2018, described good right and left ventricular function with a left ventricular enddiastolic vo- 
lume of $124 \mathrm{ml}$ and an ejection fraction of 57\%, and reiterated the patient's satisfaction with his cardiac and general state of health.

On November 28, 2018 the patient had a routine check at the oncological clinic. At this time the $\mathrm{Hb}$ value was $15.7 \mathrm{~g} / \mathrm{dl}$, and the patient reported again to be able to climb several floors without any limitations due to cardiac symptoms.

In a follow-up check about one year after the first hospital admission, i.e. on February 27, 2019, the patient continued to be clinically stable, without indications for cardiac surgery. He reported to perform daily walks of about 1 hours duration.

\section{Discussion}

Iron deficiency affects up to $50 \%$ of heart failure patients and has been associated with poor quality of life, impaired exercise tolerance, and increased mortality [7]. The case presented here shows that intravenous iron supplementation not only rendered the patient operable with respect to his recently detected colon carcinoma, but also effectively improved the cardiac symptoms he had been assessed for in the first place. His anemia and iron deficiency that was due to chronic bleeding from the colon carcinoma had given rise to, or at least greatly enhanced, the clinical signs of coronary artery disease and heart failure. Although the preserved left-ventricular ejection fraction of $\sim 60 \%$ indicated a normal cardiac function apart from aortic valve disease scientific publications demonstrated that iron administration on the one hand positively impacts mitochondrial function by improving substrate utilization and myocardial bioenergetics [8] and on the other hand reverses the reduced contractility and relaxation of cardiomyocytes caused by iron deficiency [9].

In addition randomized, placebo-controlled clinical studies in patients with heart failure reduced ejection fraction (FAIR-HF, CONFIRM-HF, EFFECT-HF) have revealed a consistent benefit on self-reported Patient Global Assessment (PGA), NYHA class and a beneficial effect on peak oxygen uptake (peak $\mathrm{VO}_{2}$ ), irrespective of the presence of baseline anemia [10] [11] [12]. Further results showed that, compared to placebo, iron substitution led to significant improvement in patient's exercise capacity as measured by the distance of the 6-minute walking test (6MWT) and it was associated with a positive impact on quality of life. Therefore, recent guidelines from the European Society of Cardiology for the treatment of heart failure recommend intravenous iron supplementation for symptomatic iron deficiency patients with the aim to improve quality of life and to increase exercise capacity [13].

In the case presented here a significant subjective improvement of cardiac symptoms like angina symptoms and complete resolution of walking dyspnea were reported only one week after the first intravenous iron infusion of $500 \mathrm{mg}$. Since such a significant symptomatic improvement is unlikely to be caused by improvement of anemia alone in such a short time period, we postulate the beneficial effect of iron substitution on myocardial bioenergetics and contractil- 
ity of cardiomyocytes to be at least partially accountable for these effects. In the present case the resolution of cardiac symptoms even led to cancelation of aortic valve surgery and other cardiac interventions.

Given this comparatively simple solution to a serious medical condition, it appears advisable to pay increased attention to iron deficiency parameters and hemoglobin levels in patients with cardiac symptoms; i.e., dyspnea or angina. This applies particularly to the setting of coronary artery disease. The scientific literature recommends higher hemoglobin levels for patients with coronary artery disease than for those without [14] [15].

Intravenous iron supplementation is an effective means to treat iron deficiency and iron deficiency anemia without the risks of a blood transfusion. In addition, as is shown by this case, it can have rapid and long-lasting benefits on cardiac function. Whether these beneficial effects are related to the increase in hemoglobin or might also be due to other effects of the iron on the heart remains to be determined. However, already 1 week after the initiation of treatment, the patient experienced marked symptom reduction, and his hemoglobin improved in a reliable manner. The right hemicolectomy was considered urgent and was performed even before the target hemoglobin level of at least $13 \mathrm{~g} / \mathrm{dL}$ had been achieved. Nevertheless, his blood counts continued to improve after a transient surgery-related decrease, and reached normal levels at the time of the video-assisted thoracoscopic surgery, although the patient had not received any further iron supplementation after the initial administration of $2 \mathrm{~g}$. Of note, the iron supplementation was not associated with any reported or observed adverse reaction.

This favorable course of events enabled the patient to undergo repeated surgery without being compromised by the initially diagnosed anemia. He was stable from the cardiopulmonary point of view throughout the postoperative periods, and he was discharged in good clinical condition. All of the subsequent laboratory tests revealed regular red blood cell counts. Meanwhile, the initial plans for aortic valve surgery were suspended, which also applied to any intention to perform coronary intervention in the long run, including stent implantation or coronary artery bypass grafting.

\section{Conclusion}

In conclusion, the case discussed here shows that anemia and iron deficiency should be considered as a potential cause of cardiac symptoms that can be brought about or augmented by the mere reduction in oxygen carriers and negative impact on myocardial bioenergetics. Intravenous iron administration offers benefits in terms of restoring erythrocyte counts, with potentially fast and sustained effects on cardiac function.

\section{Acknowledgements}

The authors thank Dr. Judith Moser for providing writing assistance. 


\section{Conflicts of Interest}

A.G. is Medical Director of Vifor Pharma Austria.

\section{References}

[1] Follea, G. (2016) Patient Blood Management. Transfusion Clinique et Biologique, 23, 175-184. https://doi.org/10.1016/j.tracli.2016.08.008

[2] Munoz, M., Gomez-Ramirez, S., Campos, A., Ruiz, J. and Liumbruno, G.M. (2015) Pre-Operative Anaemia: Prevalence, Consequences and Approaches to Management. Blood Transfusion, 13, 370-379.

[3] Clevenger, B., Mallett, S.V., Klein, A.A. and Richards, T. (2015) Patient Blood Management to Reduce Surgical Risk. British Journal of Surgery, 102, 1325-1337. https://doi.org/10.1002/bjs.9898

[4] Lin, D.M., Lin, E.S. and Tran, M.H. (2013) Efficacy and Safety of Erythropoietin and Intravenous Iron in Perioperative Blood Management: A Systematic Review. Transfusion Medicine Reviews, 27, 221-234. https://doi.org/10.1016/j.tmrv.2013.09.001

[5] Litton, E., Xiao, J. and Ho, K.M. (2013) Safety and Efficacy of Intravenous Iron Therapy in Reducing Requirement for Allogeneic Blood Transfusion: Systematic Review and Meta-Analysis of Randomised Clinical Trials. BMJ, 347, f4822. https://doi.org/10.1136/bmj.f4822

[6] Leahy, M.F., Hofmann, A., Towler, S., Trentino, K.M., Burrows, S.A., Swain, S.G., Hamdorf, J., Gallagher, T., Koay, A., Geelhoed, G.C. and Farmer, S.L. (2017) Improved Outcomes and Reduced Costs Associated with a Health-System-Wide Patient Blood Management Program: A Retrospective Observational Study in Four Major Adult Tertiary-Care Hospitals. Transfusion, 57, 1347-1358.

https://doi.org/10.1111/trf.14006

[7] Dinatolo, E., Dasseni, N., Metra, M., Lombardi, C. and von Haehling, S. (2018) Iron Deficiency in Heart Failure. Journal of Cardiovascular Medicine (Hagerstown), 19, 706-716. https://doi.org/10.2459/JCM.0000000000000686

[8] Melenovsky, V., Petrak, J., Mracek, T., Benes, J., Borlaug, B.A., Nuskova, H., Pluhacek, T., Spatenka, J., Kovalcikova, J., Drahota, Z., Kautzner, J., Pirk, J. and Houstek, J. (2017) Myocardial Iron Content and Mitochondrial Function in Human Heart Failure: A Direct Tissue Analysis. European Journal of Heart Failure, 19, 522-530. https://doi.org/10.1002/ejhf.640

[9] Hoes, M.F., Grote Beverborg, N., Kijlstra, J.D., Kuipers, J., Swinkels, D.W., Giepmans, B.N.G., Rodenburg, R.J., van Veldhuisen, D.J., de Boer, R.A. and van der Meer, P. (2018) Iron Deficiency Impairs Contractility of Human Cardiomyocytes through Decreased Mitochondrial Function. European Journal of Heart Failure, 20, 910-919. https://doi.org/10.1002/ejhf.1154

[10] Anker, S.D., Comin Colet, J., Filippatos, G., Willenheimer, R., Dickstein, K., Drexler, H., Luscher, T.F., Bart, B., Banasiak, W., Niegowska, J., Kirwan, B.A., Mori, C., von Eisenhart Rothe, B., Pocock, S.J., Poole-Wilson, P.A. and Ponikowski, P. (2009) Ferric Carboxymaltose in Patients with Heart Failure and Iron Deficiency. The New England Journal of Medicine, 361, 2436-2448.

https://doi.org/10.1056/NEJMoa0908355

[11] Ponikowski, P., van Veldhuisen, D.J., Comin-Colet, J., Ertl, G., Komajda, M., Mareev, V., McDonagh, T., Parkhomenko, A., Tavazzi, L., Levesque, V., Mori, C., Roubert, B., Filippatos, G., Ruschitzka, F. and Anker, S.D. (2015) Beneficial Effects 
of Long-Term Intravenous Iron Therapy with Ferric Carboxymaltose in Patients with Symptomatic Heart Failure and Iron Deficiencydagger. European Heart Journal, 36, 657-668. https://doi.org/10.1093/eurheartj/ehu385

[12] van Veldhuisen, D.J., Ponikowski, P., van der Meer, P., Metra, M., Bohm, M., Doletsky, A., Voors, A.A., Macdougall, I.C., Anker, S.D., Roubert, B., Zakin, L. and Cohen-Solal, A. (2017) Effect of Ferric Carboxymaltose on Exercise Capacity in Patients with Chronic Heart Failure and Iron Deficiency. Circulation, 136, 1374-1383. https://doi.org/10.1161/CIRCULATIONAHA.117.027497

[13] Ponikowski, P., Voors, A.A., Anker, S.D., Bueno, H., Cleland, J.G.F., Coats, A.J.S., Falk, V., Gonzalez-Juanatey, J.R., Harjola, V.P., Jankowska, E.A., Jessup, M., Linde, C., Nihoyannopoulos, P., Parissis, J.T., Pieske, B., Riley, J.P., Rosano, G.M.C., Ruilope, L.M., Ruschitzka, F., Rutten, F.H. and van der Meer, P. (2016) 2016 ESC Guidelines for the Diagnosis and Treatment of Acute and Chronic Heart Failure: The Task Force for the Diagnosis and Treatment of Acute and Chronic Heart Failure of the European Society of Cardiology (ESC) Developed with the Special Contribution of the Heart Failure Association (HFA) of the ESC. European Heart Journal, 37, 2129-2200. https://doi.org/10.1093/eurheartj/ehw128

[14] da Silveira, A.D., Ribeiro, R.A., Rossini, A.P., Stella, S.F., Ritta, H.A., Stein, R. and Polanczyk, C.A. (2008) Association of Anemia with Clinical Outcomes in Stable Coronary Artery Disease. Coronary Artery Disease, 19, 21-26. https://doi.org/10.1097/MCA.0b013e3282f27c0a

[15] Kulier, A., Levin, J., Moser, R., Rumpold-Seitlinger, G., Tudor, I.C., Snyder-Ramos, S.A., Moehnle, P. and Mangano, D.T. (2007) Impact of Preoperative Anemia on Outcome in Patients Undergoing Coronary Artery Bypass Graft Surgery. Circulation, 116, 471-479. https://doi.org/10.1161/CIRCULATIONAHA.106.653501 